Portland State University

PDXScholar

\title{
Workplace Motivation: Addressing Telework as a Mechanism for Maintaining Employee Productivity
}

\author{
Kaitlyn Fujii \\ Portland State University
}

Follow this and additional works at: https://pdxscholar.library.pdx.edu/honorstheses

Part of the Business Commons, Organizational Communication Commons, and the Psychology Commons

Let us know how access to this document benefits you.

\section{Recommended Citation}

Fujii, Kaitlyn, "Workplace Motivation: Addressing Telework as a Mechanism for Maintaining Employee Productivity" (2020). University Honors Theses. Paper 891.

https://doi.org/10.15760/honors.912

This Thesis is brought to you for free and open access. It has been accepted for inclusion in University Honors Theses by an authorized administrator of PDXScholar. Please contact us if we can make this document more accessible: pdxscholar@pdx.edu. 


\section{Workplace Motivation: Addressing telework as a mechanism for maintaining employee productivity \\ by \\ Kaitlyn Fujii}

An undergraduate honors thesis submitted in partial fulfillment of the requirements for the degree of

Bachelor of Science

In

University Honors

And

Business Administration: Marketing \& Advertising

And

Psychology

Thesis Advisor

Jennifer Loney

Portland State University

2020

Table of Contents 


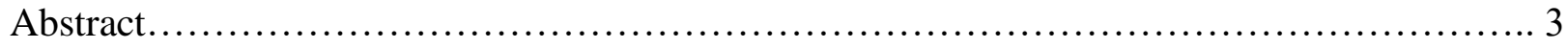

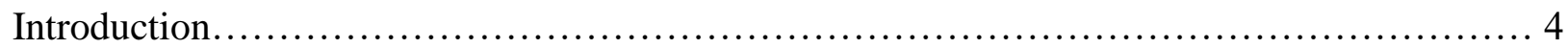

Historical Background..................................................... 6

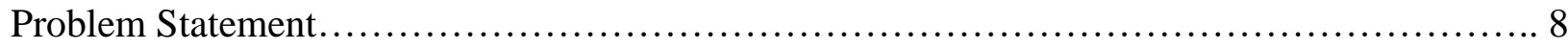

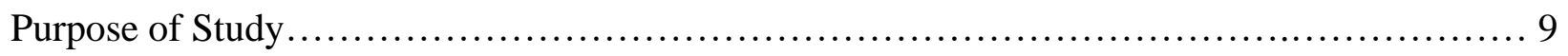

Thesis Statement............................................................... 10

Theoretical Framework............................................................. 10

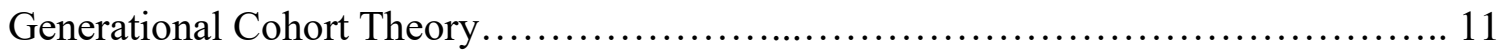

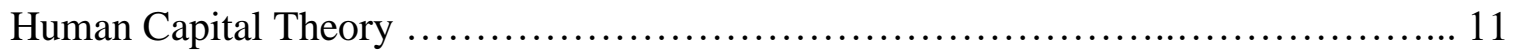

Work Motivation Theory............................................... 12

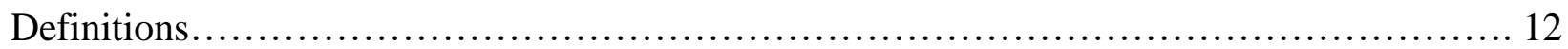

Literature Review........................................................... 15

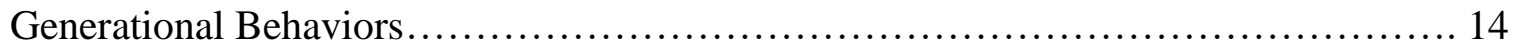

Telework: New Horizons................................................... 20

Enhancing Motivation and Workplace Productivity............................ 23

Limitation \& Future Directions..................................................... 27

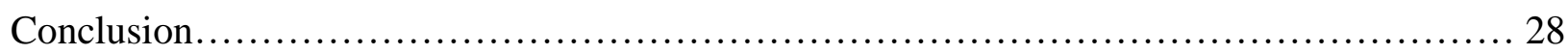

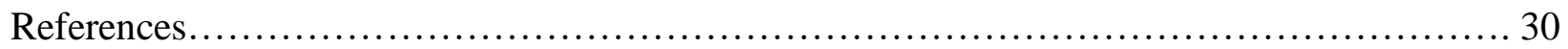




\begin{abstract}
This research seeks to identify social and psychological factors that affect satisfaction levels of millennial and gen-z employees. The thesis suggests teleworking as a renewed tool for communicating, motivating, and executing work in organizations to increase productivity. The main factors identified for said analysis have been determined through the study of business and academic literature about workplace culture and how it is changing. The research at hand investigated the differences between baby boomer, millennial and gen-z employees and how participating in telework may enhance their output. For analysis, three theories were referenced in relation to age, productivity and motivation. Generational Cohort Theory, Human Capital Theory and Work Motivation Theory were used to provide a more valuable and informed understanding of how telework is effective. The findings presented in this paper can be continued through qualitative interviews and case studies of companies using telework as a resource for increased employee productivity and motivation.

Keywords: Telework, productivity, motivation, communication-process, engagement, performance reviews, work-life balance, telework, remote work, distributed work, virtual work, flexible work, flexplace, distance work
\end{abstract}


Workplace Motivation: Addressing telework as a mechanism for maintaining employee productivity

With this research spanning from September of 2019 to May of 2020 it is imperative to acknowledge COVID-19, and the global pandemic, enforcing a mandatory stay at home order nation-wide. Additionally, the order drew instant attention to and widespread adoption of the research topic of telework. The virus called for rapid and radical transition of all industries to remote work. Additionally, compiling trauma due to loss of work in physical workplaces, inability to attend school, and the limits imposed on personal freedom generated a universal buzz surrounding mechanisms of virtual communication and telework.

This research seeks to unveil differences amongst baby-boomer, millennial and gen-z generations in how they interact within the workplace. Due to retirement, the baby-boomer generation is exiting the workforce at a rapid pace, and millennial and gen-z workers are transitioning into their roles (Schawebel, 2018). Before this global pandemic, all baby-boomers were expected to retire in the coming decade; this virus may accelerate the retirement timeline or may prolong their employment, similar to the 2008 economic slump (US. G.A.O., 2013).

Moreover, it is likely that the primary experiences that introduce millennial and gen-z workers to their professional careers will be executed virtually, due to the universal pandemic mandating the general public to stay at home. By $2025,75 \%$ of the global workforce will be comprised of the Millennial generation (Schawebel, 2018). Naturally, new workplace expectations and environmental pressures for corporations are appearing to adhere to differences in the priorities of millennial and gen-z workers in comparison to the baby boomer workers of the past (Forastero, et.al, 2018). The retirement of the baby boomer generation is noteworthy in comparison to that of the g.i. and silent generations. Variation of behavioral norms is interesting 
as there is a stark contrast due to the use and knowledge of digital communication technology. The introduction and use of technology for the millennial and gen-z generation has changed their motivation factors, along with their communication access, process and needs (Downing, 2006).

In comparison to baby boomers, both millennial and gen-z workers grew up in an era of rapidly evolving digital technology. Digital technology brought a new wave of business, and a new way to do business. As something vastly different than anything before it's time, the digital era brought rapid development, industry shifts, and the ability for instant communication.

Currently, digital communication utilizes highly functional technological systems (Zoom, Skype, Google Meet, WebEx, etc.) in lieu of in-person, face-to-face interactions. These telecommunication options expand communication effectiveness for the employee, company and client. Changing from in person communication, to online has positive and negative consequences that will be discussed further in the paper. In addition, the increase in all virtual communication options (text message, Instagram, email, Twitter, etc.) has changed the communication process forever. However, this shift in person to person interaction have implications that reach beyond the scope of this paper.

This paper highlights the use of digital technology, used to telework, as a method for increasing productivity and motivation. Specifically, adopting telecommunication platforms allows for companies to innovatively offer work-space variety to lifestyle oriented millennial and gen-z workers. Additionally, enhanced work-life balance is a positive effect resulting from combining factors such as communication technology and office space variety (Ankli \& Palliam, 2012). Productivity and motivation are primary drivers of workplace success and therefore, for organizational effectiveness, it is essential to understand how to maintain these in 
transformational times. The following research analysis will identify key fundamentals for motivation and how they translate into the professional work environment.

Data gathered for this thesis incorporates theories from workplace psychology, in which Herzberg's two-factor theory directly ties together motivation and workplace productivity. It has long been projected that telework will be a dominant workplace model, but it has been unclear when this transition was to take place (Pasini \& Back, 2018). With the introduction of COVID19, known telework mechanisms were forced upon employees and employers to maintain and execute workplace functions. This remote work environment has highlighted both the positive and negative consequences of telework in real time. Due to worldwide shutdowns, virtual communication effectiveness is now understood across industry, and on most individual levels. COVID-19 allowed for a strong statement to be made that this method of working should continue after restrictions are lifted; there are now a number of companies stating employees may continue to work from home even after the shutdown.

Foremost, this research seeks to close the telework knowledge gap so that business professionals can understand how this tool can be utilized beyond COVID-19 as an increasingly valuable communication tool and asset to the workplace. This will be accomplished by defining telework and identifying how a teleworker's ability to work off site affects productivity, motivation, and work-life balance.

\section{Historical Background}

Telecommuting as a workplace model was informed by Jack Niles in 1973. His model of telework, displaying how telecommuting can be utilized to reduce traffic, lead the US government to pass a flexible work arrangement (FWA) policy to grant flexible schedules for federal employees (Telework, 2014). The 1970's oil crisis was the primary call for an innovative 
way to reduce energy consumption. Influence of government intervention was maintained through the passing of the Clean Air Act Amendments of 1990, which increased awareness around air quality and the need for alternative energy sources (Pasini \& Back, 2018). Businesses were looking for ways to adjust their own energy consumption; the development of telecommuting arrangements provided an alternative and innovative way of satisfying this requirement.

Another notable policy change is The National Telecommuting Initiative of 1996, which marked the federal government's confirmation of support for increased telework opportunities nationwide (Hering, 2015). This policy change provided a mandate for states to revise employee handbooks to include options for employee commuting programs. Telecommuting evolved in the 1970 's from a construct intended to address traffic problems and energy consumption to a mechanism for addressing workforce issues, recruiting programmers, and managing familial responsibilities. Adaptations of telecommuting methods, such as telework, also surfaced during this time. Much of this can be credited to the rapid and dramatic influx of technology into the operating economy. The virtual communication medium has increased its capabilities due to home computing as well as the shift in the economy from manufacturing to information-based. In 2010, the U.S. Telework Enhancement Act became law and mandated executive agencies to establish and implement policy to authorize telework options for employees (SHRM, 2018). Telework continues to receive attention due to its potential to achieve positive outcomes -employee morale, work-life balance, new communication pathways, reduced overhead costs, etc. (Telework, 2014). Advancements in information and communication technologies enabled the concept of telework as an alternative to the traditional office setting. These attributes contribute 
to overall job satisfaction, which is essential for employee retention as it has a direct relationship to job turnover.

Overall, telework remains relevant today due to advantages this mechanism brings to market-competition issues, overhead cost control, commuting and environmental issues, and local policy initiatives (Hoornweg, et.al, 2017). The concepts of telework and telecommuting are often used interchangeably, however it is important to acknowledge the significant distinction between the two. Telecommuting implies a total elimination of daily commuting to the central office whereas telework refers to the practice of employees performing work in spaces alternate to the office (home, coffee shops, libraries). The present research focuses on telework, which means that the employee is still a part of the office structure and can chose to report either to the home office base or to work remotely. This is because the frequency, or intensity, of telework must be considered. For instance, there are drastic differences between managing an employee who is never in the office than an employee who is in the office part time (Hoornweg, 2017). Therefore, this research does not, and cannot, make any recommendations regarding telecommuting programs, or those that are exclusively remote.

\section{Problem Statement}

In calendar year 2018, baby boomers made up 40 million jobs in the labor force (Parker, et.al, 2019). Given the need to replace 40 million of these individuals, due to retirement waves over the next 10 years, it is essential for recommendations to be made to effectively attract and retain millennial and gen-z workers. It is essential to hire workers of these age groups to meet the needs of industry in an increasingly competitive marketplace. Millennial and gen-z workers are a valuable cohort to tap into for employers; in order to ensure the correct employee hire, companies have to be more receptive towards their expectations (PricewaterhouseCoopers, 
2012). On top of these multi-generational challenges, $91 \%$ of organizations report concern over their ability to keep their workforces engaged and motivated (Bennet, Pitt \& Price, 2012). By rewarding performance with the option to telework, the $91 \%$ statistic should decrease. Herzberg's Two- Factor Theory posits that orders are motivated when recognized for their quality performance, enhancing internal reward systems to offer incentives such as telework can help organizations increase workforce engagement and motivation, and decrease fear around personnel turnover.

New work practices such as telework require a change in organizational culture. This change to policy and workplace structure has been met with resistance due to traditional value systems dominating the work environment (Kaczmarczyk, 2008). Organizational managers are reluctant to accept telework as an effective substitute for reporting to a central office space (Pyoria, 2011). The literature reviewed for this paper sought to understand and change this thought process to encourage companies to take advantage of telework for millennial and gen-z workers.

\section{Purpose of Study}

This research specifically focused on understanding whether or not telework is a valuable and attractive mechanism, for millennial and gen-z workers, and how it can be incorporated into current culture (Eversole, et.al, 2012). There is currently limited information discussing how to effectively support and maintain vital workplace relationships with millennial and gen-z workers; businesses are nervous about their ability to inspire employee retention. Through identifying the needs of these workers, this research will contribute to the discourse of human relations and management by recommending telework as a method to retain a strong and productive workforce of valuable employees. 
Millennial and gen-z employees will make up the majority of the workforce in the near future: it is important to gain an understanding of their demographic needs. This understanding is essential as it allows for management and company culture to evolve. Overall, there is a call for increased receptivity to employee needs in order to sustain competitive advantage in the talent acquisition market. This research seeks to prove the importance of work-space flexibility, specifically pertaining to workplace, in order to become future-oriented and need-based. It is the hope that this research provides insight into how telework can positively influence employee's motivation and productivity, which will in turn allow for recommendations to be made for how to successfully implement telework into a current system.

\section{Thesis Statement}

This paper seeks to understand the role of telework in the post-baby boomer workforce as a mechanism for increasing productivity through enhancing employee motivation and work-life balance. This will be accomplished by investigating what motivates millennial and gen-z employees to be productive through a thoughtful analysis of academic research in the areas of generational attitudes around work life balance and telework. Academic research will be used to make an informed recommendation for management structures to utilize telework as a flexible work arrangement.

\section{Theoretical Framework}

Three main theories were reviewed and explored to best determine how to approach employee needs and motivation (a) Generational Cohort Theory, (b) Human Capital Theory, and (c) Work Motivation Theory. These theories are appropriate because the Generational Cohort Theory offers valuable support for the literature review comparing Gen-z, millennial and baby- 
boomer workers. Additionally, Human Capital Theory acknowledges the importance of companies attracting talent, and Herzberg brings to light the nature of humans to put their energy into action that contributes to their own needs. Furthermore, work motivation theory states that by acknowledging quality work from an employee there is a direct impact on motivation and productivity levels.

\section{Generational Cohort Theory}

William Strauss and Neil Howe define a generation as a social construct. Individuals born at similar times are influenced by historical and social contexts of their period. These experiences are so distinct from each other, they are able to divide generations into separate cohorts for study. Currently, most organizations have four generational cohorts among their employees: baby boomers, gen-x, millennials and gen-z. This is a valuable lens because ultimately employees from different generations may have varying expectations of what they expect from their work environment (Alter, 1991).

\section{Human Capital Theory}

Human Capital Theory dictates that learning is a lifelong process and that those with the strongest education, skills, talents and abilities will be the most sought after by employers and also the highest earners. The most successful companies will be those who invest in the training and knowledge of their workers. This investment leads to productive, quality employees and successful industry innovation. In order for an employer to remain competitive in the market, they must maintain a network of workers that are innovative and adaptive (Nafukho, 2004). Investment in human capital, either on the individual or company level, is necessary for generational industry success. 


\section{Work Motivation Theory}

It is critical to understand the values of employees in order to ensure workplace satisfaction and the effective use of rewards to motivate behavior. In his two factor, motivationhygiene theory, Herzberg states motivation is influenced by the extent to which the job offers opportunity for reinforcement and recognition (Brown, et.al, 2017). The achievement, responsibility and growth within a role is the most important driver for employee satisfaction and motivation. Internal factors such as these are what Herzberg refers to as motivators. This is valuable, as when employees are motivated, they are successful in their performance and in turn grow their professional opportunities. On the other hand, external hygiene factors such as office location and company policies do not contribute to long-term motivation (Herzberg, 1971).

\section{Definitions}

This research utilizes a series of adapted definitions (ref. table 1) to establish a mutual understanding of the jargon used in discussion.

Table 1

Telework An alternative work arrangement in which employees regularly spend part of their allotted work hours away from the traditional office space. This hinges on the principal that much of the modern business workforce is no longer limited by physical logistics of the traditional worker. This is specific to careers in which workers solely utilize communication, information and data rather than industrial machinery and raw materials (Schweitzer \& Duxbury, 2006). This mechanism is either to be 'employee-oriented' when an employee works at home to address his and her family-related or personal wants or needs, and 'employer-oriented' when an employee works at 
home due to the employer's strategic or operational objectives (Cooke, et.al., 2014).

Telecommuting This way of work execution mandates a travel reduction, or elimination of commute, from home to office space. This means the worker does not report to the traditional office setting and work solely from a separate home base under remote supervision (Lachapelle, et.al., 2018).

Motivation The process by which activities begin, direct and sustain themselves to meet expectations required. This is an internal state that activates behavior to give direction, and intensity behind actions. Underlying assumptions of this practice include: the individual capacity for responsible actions, the natural aspiration to learn and understand, and the desire to excel at work and play (Ankli \& Palliam, 2012).

Productivity A measure of how employees within an organization, produce value from the materials provided to them. In other words, how much work is accomplished in the given environment over a given period of time that generates a positive outcome for the organization. Productivity serves as a spectrum to analyze the functionality and practicality of an employee's role (Hong, et.al, 1995).

This serves as an important predictor and measuring element for motivation (Kuo, et.al., 2017).

Work-Life

A new facet of workplace culture, this construct is derived from a Balance collection of studies that show direct positive affect between achieving an appropriate balance between life inside and out of work. This implementation increases the satisfaction of workers and increases loyalty by prioritizing the basic needs of workers including 


\begin{tabular}{ll}
\hline family, social, achievement, promotion, income and commuting, etc. \\
needs (Gassan, et.al., 2020). \\
A combination of positive or negative feelings workers have towards \\
Satisfaction $\quad$ their job. Job satisfaction represents the extent to which an \\
individual's expectations meets the rewards offered by their employer. \\
It is tied to a sense of achievement and success on the job. \\
Satisfaction is known to be directly linked to employee productivity \\
(Aziri, 2011) \\
Defined as the loss of talent in the workforce. It is necessary to \\
understand the rate of employee turnover as a predicting variable for \\
productivity and morale (Golden \& Dino, 2008).
\end{tabular}

Baby Boomer Membership is given to those born between the years of 1943-1960. About 68 million Boomers currently reside in the United States, composing about 30\% of today's workforce. This population is marked by a massive number of occupants due to a rapid boom in the US birth rate in 1957 (Yang \& Guy, 2006).

Millennial Cohort born between the years of 1978 and 1995, and currently compromises $14 \%$ of the workforce in the United States. This statistic is rapidly increasing as the younger members of this generation enter the workforce (Ehrat, et.al., 2010)

Generation-Z Considered to be formed by those who are born after 1995, recognized as digital natives as they enter the labor market, new generational ideologies will bring charismatic expectations for professional working environment (Iorgulescu, 2016). 


\section{Literature Review}

This review collected, analyzed and synthesized the literature written around the general topic of telework to connect it to literature about motivation and productivity. The researcher accumulated a collection of data looking specifically for more current research, as the field of telework is rapidly evolving. This evolution is due to the unexpected COVID-19 pandemic and the immediate need for social distancing, and remote work options. The collection of information on this topic continued throughout the writing process. Research was gathered for this paper between September 2019 and May 2020 to incorporate the use of telework during the pandemic.

\section{Generational Behaviors}

As acknowledged in the background section of this paper, telework and other alternative work practices have been met with resistance and distrust leading to a lag in its adoption. This resistance has been growing weaker due to the influx of the millennial and gen-z employees along with the retirement of baby boomers. In addition, the COVID-19 pandemic acted as a catalyst for telework and its acceptance by all generations.

As the demographic composition of the modern workplace is expected to finish its shift in the next 10 years, it is valuable to understand why telework technology has not been previously utilized. This is because perceptions of millennial and gen-z workers account for virtual work and will soon dominate the business environment.

\section{$\underline{\text { Millennial and Gen-z vs Baby Boomers }}$}

Age is a widely accepted predictor of attitude and behavior. Utilizing age as a frame of reference allows for researchers to analyze differences amongst generations to strengthen understandings around behavioral norms (Tsaur \& Yen, 2018). The workplace is diverse in age, 
gender, education and status and it is impossible to motivate all employees with the same incentive package (Radovic, 2014). The literature review demonstrated that generational cohorts find meaning in their work through a multitude of channels. Furthermore, referencing generations as individual cohorts offers a valuable lens to gauge how new business practices will be accepted in the changing workplace. Through comprehension of behavioral tendencies, organizations can be more receptive to their employees' levels of satisfaction within their role and take action to implement changes if they notice negative response outcomes (Bishka, 2015).

Additionally, age is important for understanding how employees react to workplace stressors and respond to new implementations. For the sake of this research, it is argued that age serves as a valuable mechanism for gauging positive adoption of new business practices. As the millennial and gen-z workers overtake the baby boomers in the workforce, technologies that suit the preferences of these new generations will become dominant. In reference to the Theory of Human Capital, the more knowledge we have as individuals actively contributes to our economic value. This indicates that the more receptive understandings of workplace technologies by millennial and gen-z workers actively contributes to their economic value, and also demonstrates the need to retain employees in these cohorts (Nafukho, 2004).

There are specific generational effects that occur during the childhood development process which actively contribute to how the fundamental needs of an individual are formed. By looking at the time of childhood development, researchers can predict how individuals will react to new ideas (Murdock, 2019). The Generational Cohort Theory allots differences in behavior amongst generations to specific historical and social events that occurred during the developmental process. Boomers did not grow up during the technological evolution. Overall, information and communication technology were learned later in life and therefore do not come 
as naturally (Leuty, 2014). In comparison, millennial and gen-z generations are extremely comfortable using technology to communicate. Generally, it is their main mode for communication. They have grown up with the Internet and are highly connected overall; they use technology to track trends and stay current. Millennial and gen-z workers are receptive to innovation and technological advances (Au-Yong-Oliveira, 2018). These generations accept, embrace and encourage new technology as they understand the potential for to business to benefit.

\section{$\underline{\text { Workplace Stereotypes }}$}

It is generally recognized that the baby boomer generation is not particularly adherent to new technologies and workplace systems. This stereotype was tested in a 2006 study which analyzed the perceptions of 496 undergraduate students at a large, public, western university. In this study, participants were prompted to rate adaptive characteristics within their work environment against 7 targets of different ages (DeArmond, 2006). Overall, the study sought to directly test the effects of age bias on the acceptance of adaptability components. It was found that older workers are at particular risk for being perceived as less capable of learning new tasks, technologies and workplace systems. By limiting cultural and physical adaptability through stereotyping this demographic, it was perceived that boomers are particularly resistant to change in the workplace. In addition, it was perceived that the age stereotype negatively impacts the performance of older generations (DeArmond, 2006). With this study in mind, adaptability components are more likely to be encouraged by millennial and gen-z workers. These employees are perceived to be engaged by, and open to, changing workplace systems, rather than baby boomers who are perceived to be resistant to change. 
De Armond's study referenced the 1999 Campbell model, which specifically speaks to methods for maintaining job performance. His model recommended adding adaptability components to workplace systems to be more adept for handling crisis and stress, as well as solving problems creatively. As technology enables organizations to adjust to dynamic workplace changes, a premium is placed on employees who are able to adapt to these technologies (DeArmond, 2006). Therefore, when adding this component, organizations should be particularly mindful of the potential merit behind the age stereotypes tested in this study for resistance to adaptive job characteristics.

\section{Entrance of Younger Generations}

Millennial and gen-z workers will compose $75 \%$ of the workforce in the coming 10 years and workplaces that utilize adaptable work components will be highly attractive to these workers (Wright, 2015). Analyzing the generation of workers that will replace the baby boomers will help predict the need for adaptable workplace components; this in line with the Generational Cohort Theory which acknowledges the importance of the generational lens in the workforce. Work Motivation Theory highlights the need to remain receptive of employee attitudes in order to be a competitor in the employee market. Overall, millennial and gen-z workers benefit positively from selecting workplace rewards that acknowledge their individual needs (Mirjana, 2014). Workplace behaviors are expected to completely shift because generational divides prompt different behavioral responses. In the case of millennial and gen-z workers, traditional workplace elements such as (a) longer lunch time frame, or (b) a front row parking spot are not particularly appealing. Incentives such as these can contribute to feelings of boredom in the workplace (Forastero, et.al, 2018). During this 10-year transitional period, organizations need to maintain a competitive edge to attract and maintain high level talent. 
Kelly Pledger Weeks and Caitlin Schaffert developed a workplace specific model to identify the changes that are taking place in employee wants and needs due to generational differences. This model offers valuable supporting information for the development of this thesis and references generational divides as the primary predecessor for employee preferences. Generational divides are a huge moderating effect for differences in perceived value of work, and thus directly contribute to understanding how to address motivational needs on an individual scale. The generational effects of the boomer generation indicate a strong desire to have a central office space, low work-life balance, attention and both social and altruistic values (Weeks \& Schaffert, 2019). In comparison, millennial workers were found to score low on scales that inquired about intrinsic reward systems, social needs and the need for work-place centrality; they were found to have high scores in freedom seeking and work-life balance (Weeks \& Schaffert, 2019). This indicates an obvious separation between what each cohort needs to produce quality work. Previous realities of the need for a social system and central office space have been replaced with needs for freedom and opportunities to enhance work life balance and fulfill other untraditional needs (Maruyama \& Tietze, 2012).

More specifically, individuals have the authority to decide which hours work best for them to complete work, where they would like to be physically for the duration of their workday, and how much time they spend during their workday engaging in non-work-related conversation. As research suggests, millennials and gen-z do not value social interaction in the workplace, nor do they observe discrepancy in productivity between work environments as traditional workplace norms suggest they should. Thus, telework is a valuable tool to enhance their work experience. This tool has the ability to transform the workforce through fulfillment of job 
assignments from any space around the world; this allows for achievement of work-life balance which is a primary driver of millennial and gen-z employee satisfaction (Davis \& Cates, 2013). With Herzberg's Two Factor model in mind, not meeting the needs of millennials and gen-z workers will actively contribute to levels of dissatisfaction in the work environment: however, simply acknowledging them as needs is not enough either. This model is particularly useful for this research as it indicates the need for a growth factor to be implemented in order for satisfaction to increase. This means that flexible work opportunities must be earned and furthermore contribute to the content and opportunity of the work at hand. As millennial and genz workers score high in freedom seeking and work-life balance scales, telework is a valid offering as it enhances work life balance while simultaneously providing an employee with freedom.

\section{Telework: New Horizons}

This thesis argues that development of flexible work arrangements that integrate telework as a flexible work arrangement is transformative for millennial and gen-z employees as the incentive enhances their job role and acknowledges their individual performance.

\section{A Changing Environment}

Telework practices are currently being utilized world-wide due to the global COVID-19 pandemic. Since 1990 there has been speculation about telework dominating business practices, however traditional office settings have remained the most relevant (Torten, 2016). Traditional business practices have been turned upside down due to COVID-19 and telework has become the new normal.

The points of debate stem from traditional corporate cultures that are unsupportive of more progressive, employee expectations; research has pinpointed the barrier to telework 
programs as the general attitudes of business leaders (Forgacs, 2010). Factors include risks coinciding with loss of power, misunderstandings of cost-value, inability to empathize, personal preferences, liability concerns and intellectual property rights (Calvasina, et al. 2012). However, due to COVID-19, it has been made clear that organizations are able to create and use telework systems to support and maintain employees working out of a home office space. Widespread adoption of this practice due to mandatory stay-at-home orders demonstrates that this work system is highly effective and adaptable. In fact, it has been shown that at least $56 \%$ of the current workforce holds a job that is compatible with remote work (GWA, 2020). It has been suggested that a $25-30 \%$ uptick in telework will occur by the end of 2021 due to increased demand, reduced fear about working from home, increased pressure for disaster preparedness, reduced travel and increased awareness of cost saving opportunities (GWA, 2020). Presently, it is difficult to determine whether or not the factors listed previously for barriers to telework programs are still of primary concern. The individuals questioned under research studies have not been revisited with reference to the new global pandemic. It will be interesting to see what studies conducted post COVID-19 will learn about remote work programs.

What is currently shown is that in the past decade, many organizations have broken through traditional boundaries to become more flexible, diverse and established. An observable spike in telework options across industry took place between 2010 and 2013 due to increases in adoption of workplace technologies and new waves of industry such as social networking and online retail purchasing, online messaging systems, etc. (Wise, 2016). As reported by the Society for Human Resource Management 2010 annual survey, 59\% of employers offer different forms of telework including allowing for one telework day a year, allowing for part time telework and a few offering full time telecommuting roles (SHRM, 2010). The increase is also highlighted by 
the 2013 WorldatWork census which uncovered $88 \%$ of organizations offered telework options to their employees (Allen, et. al, 2015). The observable increase in telework practices amongst the two studies reflect a recent trend around business professionals craving more and more flexibility in the workplace, this can also be attributed to the generational change away from baby boomers in the workplace. Researchers state the desire for flexibility as the primary reason for the rapid increase of work-life balance projects such as telework and adherence to Work Motivation Theory (Maruyama \& Tietze, 2012).

\section{$\underline{\text { A Case Study }}$}

Mark J. Vitry conducted several case studies focused on senior level managers, from a variety of small and large organizations, who are currently actively participating in leadership activities of their company's telework programs. Within the study, one company implemented a trial telework program for an employee for 60 days and used a tool to measure improvements in productivity levels. Overall, findings produced a $96 \%$ increase in productivity, demonstrating the capabilities of the telework program (Vitry, 2013). Following the success of this employee's telework, the organization offered the telework program as a reward for the highest performers. The organization maintained the measurement criteria for productivity, and similarly to the individual implementation the organization found productivity levels of telework employees increased significantly (Vitry, 2013). After the case study was conducted, the organization proceeded to modify internal operations in order to accommodate more employees utilizing telework systems. After one year, the telework program overall reported positive effects on employees due to reduction in interpersonal conflict and cost savings for the organization. Ultimately, the most beneficial outcomes of the new telework system for this company were the 
increase in productivity with better quality output and the decrease in overhead costs (Vitry, 2013).

\section{Enhancing Motivation \& Workplace Productivity}

This paper confirms that offering telework to millennial and gen-z employees can increase motivation and productivity levels.

\section{Motivation in the Workplace}

Employees are motivated by the expectation of receiving a benefit or reward, either intrinsic or extrinsic. Whether that be a higher salary to support their family, vacation time to explore the world, a thank you from customers, or an acknowledgement from management, these incentives are necessary to maintain a productive and impactful work force (Maruyama \& Tietze, 2012). Motivators tend to be intrinsic and are often unnoticed by the conscious mind but are the drivers of employee satisfaction (Sale \& Jones, 2019). As previously acknowledged, motivation is also the primary predecessor to quality performance. Thus, to be effective, human resource departments must work to enhance compensation packages and performance appraisals in order to subliminally direct employee action towards proficient completion of objectives (Ahmmad, Lee, \& Shoham, 2015). Due to a changing workplace demographic structure, previous methods of enhancing workplace motivation are not receptive by millennial and gen-z workers.

A research study conducted by AON Hewitt on employee engagement of millennials in 5 regions (Asia, Pacific, Europe, Latin American, and North America) demonstrated millennials report lower levels of workplace engagement in comparison to baby boomers (Forastero, et.al, 2018). This was due to one or more of the following factors of their job: not being engaging, not aligning with their value system and not offering individual agency (Forastero, et.al, 2018). However, as the workplace will be largely dominated by members of this particular cohort by 
2030, it is strategic to implement new benefit programs, such as telework, to keep these vital employees engaged, motivated and productive. Newer members of a work environment are likely to intrinsically motivate themselves in response to promised benefits that appeal to their self-determined needs (Hong, 2015). In addition, millennials are particularly loyal to companies who offer high flexibility and autonomy as this is what they acknowledge to be their primary workplace needs (Sale \& Steve, 2019).

Once again, it is recognized that a massive wave of baby boomers is expected to retire in the coming 10 years. Analyzing the generation of workers that will fill their shoes is necessary to remain predictive with business practices; the Work Motivation Theory highlights the need to remain receptive of employee attitudes in order to be a competitor in the employee market. Overall, millennial and gen-z workers benefit positively from selecting workplace rewards that acknowledge their individual needs (Lam \& Lambermont-Ford, 2010).

\section{Why Telework?}

Telework can be a strong, innovative incentive for enhancing motivation by meeting individual employee needs such as essential childcare requirements, flexible work hours, or remote work options. Flexible work hours created by telework decreases congestion at rush hour and decreases the employees carbon footprint. Remote work options also allow employees to work from home, reducing the need for childcare and the cost of commuting. All of these opportunities increase employee autonomy and motivation (O’Neil, et.al, 2009). This is valuable as autonomy is something millennial and gen-z workers report as an important workplace desire (Hong, et.al, 1995). Moreover, employee autonomy contributes to increased self-efficacy, job satisfaction, and decreased personnel turnover (Parker et.al, 2013). These factors directly contribute to a secure business workforce, an important asset for human relations professionals 
and management teams to maintain (Hart, 2016). This is reinforced by a 2012 study of British Telecommunications PLC, in which more than 80 percent of respondents reported that because of greater control over the working environment, they were able to get more work done, reduce commuting stress and obtain greater flexibility (Bernardino, et.al, 2012

In addition to autonomy, individual productivity is one of the most acclaimed telework gains in the literature reviewed (Di Martino \& Wirth, 1990; Dubrin, 1991; Hartman, Stoner, \& Arora, 1991; Gajendran \& Harrison, 2007; Dahlstrom, 2013). In particular, work hour flexibility contributes directly to employee productivity. Not being confined to typical working hours allows for teleworkers to produce work in the hours in which they are most productive (Eversole, et.al, 2012). Flexible hours are a major incentive as individuals may be more productive in the early morning, or late at night; some may do better with work spread through the day with onehour breaks. Whatever the work pattern may be, individuals with high self-efficacy produce faster and higher quality work when they have direct control over their working hours. Individual performance directly contributes to business performance; therefore, HR professionals must continue to increase individual employee motivation and productivity in their workforce. Telework will help HR professionals to be successful in this endeavor (Gifford, 2015).

\section{$\underline{\text { Successful Telework }}$}

Not all jobs are conducive to telework. The first task an employer needs to accomplish is to identify the jobs that can use telework and the jobs that cannot (Tarallo, 2018). Maintaining this motivation through something other than telework will lower turnover as well.

Once a company establishes that there are jobs that can use telework, the second task is for the company to create a telework policy. This policy should be created through input from management and employees along with what has been successful in other companies using 
telework. The new policy should incorporate questions in regard to trust issues, teamwork concerns, virtual presence options, communication techniques, customer service needs, office space options, performance measures, result measures, and technology support (Tarallo, 2018). The third task is training employees on telework and its expectations. The fourth task is actual use of telework by the employees. The last task is measurement and result capturing of the telework employees. This paper will not present all the detailed tasks to incorporate telework into a company; instead it looks to encourage the use of telework to increase productivity and motivation in millennial and gen-z employees and the need to understand there will be a process to follow.

There are two items to think about when creating a telework policy. The first item occurs during the second task; it is important to understand how telework could be used within the organization before creating a policy. Management teams need to identify the achievements they wish to see from employees as a result of this work. The needs and expectations of the business are the primary concern here, as this is what brings in the money to support employees and business functions. The needs and expectations of employees are secondary to meeting the bottom line in any company. The second item occurs during the third task; telework is not suited for all employees. Not everyone has the same set of personality traits that allow them to thrive in an environment with limited authority, check-ins and face-to-face interaction (Daniels, 2000). It is essential to analyze the employee's ability to be intrinsically motivated and self-sustain prior to letting them telework permanently. It also important implement a system of check-ins to regularly evaluate the teleworking employee's output and perceptions towards the work arrangement. If there is no decrease in productivity, the employee is successfully executing telework. Examples of testing for this system can include trial and error periods, personality 
testing, or asking individuals to apply to become a teleworker (Gajendran \& Harrison, 2007). By evaluating which employees will be most successful in telework positions, companies can help guide positive outcomes.

\section{Limitations \& Future Directions}

This research exclusively used secondary research in the form of literature reviews as its basis. To continue with this topic and research, with approval from the Institutional Review Board, further researchers should gather primary data from human subjects to contribute to the base of knowledge presented in this paper.

As mentioned within this thesis, telework has many valuable attributes in addition to increasing employee motivation, flexibility, productivity and decreasing employer costs. These include: (a) decreases in carbon emissions, (b) decreases in employee stress, (c) increases in employee autonomy, (d) decreases in overhead costs, (e) reduced congestion, (f) operation effectiveness, and (g) decreases in interpersonal employee conflict. These are also important factors to consider when implementing telework as this research study barely scratched the surface of this mechanism as tool for benefiting organizational practices. The paper laid the foundation for a future study to take place analyzing the effects of telework as a motivating mechanism in the workplace.

Additionally, it is of interest to understand how telework can contribute to other aspects of the business environment. Throughout the research completed, many benefits for implementing this work system were noteworthy. First and foremost, as traffic patterns continue to become more congested, commutes will take twice as long and national productivity will dwindle. Currently, the nation experiences an economic loss of $\$ 78$ billion dollars in productive labor hours due to traffic jams (Global, 2020). Another possibility is that telework can reduce 
overhead costs significantly for companies. It was noted that all U.S. companies could increase their bottom lines between $\$ 525-\$ 665$ billion dollars annually by switching to an entirely remote workforce, it is of interest to understand how this can be scaled for when employees chose to work part-time in the office (Global, 2020).

Ultimately, the ideal workplace is one in which all employees are offered equal opportunity to develop, grow and thrive. Utilization of this research can assist with factual information regarding the capabilities of teleworking system. Through trial and error businesses can understand whether or not a telework system can be used in their operating environment. This is essential as telework systems are not for every business and are not fitted for individuals with low self-management skills and high social needs (Global, 2020). Helping organizations successfully implement and adapt telework arrangements can reduce fears around employee turnover and loss of valuable employee assets.

\section{Conclusion}

The structure of the paper and its corresponding research were laid out in September of 2019; during this timeline, the virus known as COVID-19 swept the globe and brought telework into the lives of many. Telework has become the new normal in many organizations; companies such as Twitter have extended the ability to work remotely as a permanent part of their employee packages (Heater, 2020). The pandemic allowed employees of all generations to glimpse life as teleworkers. What was found during this forced remote work situation, was that telework is highly doable for some positions and employees, but not for others. From the employer perspective, understanding the personal needs and abilities of employees will identify their best work-environment structure. 
As a whole, this paper seeks to understand the role of telework in the post baby-boomer workforce. Telework is recognized for its ability to enhance motivation and contribute to productivity due to autonomy over the direct working environment. The literature reviewed explained why generational differences are causing a change to the existing workplace system. Due to baby-boomers retiring and the number of millennial and gen-z workers increasing, the traditional, historical structures and motivation mechanisms in place will no longer be effective. The list of workplace expectations from millennial and gen-z workers require workplace transformation; this transform will include the adoption of telework systems to allow for fulfillment of job assignments apart from the traditional office space. Overall, motivation is an essential part of an effective workforce as it contributes directly to productivity. Telework, if planned and managed successfully, is an opportunity for a company to build motivation and productivity among its employees. Based on the increase of millennial and gen-z employees, telework can also be used as a strategic talent management initiative to attract and retain employees.

This paper presents telework as a methodology that is creative, cost-effective and forward thinking for the new generation of employees. Moving forward, this thesis offers telework as the incentive to enhance employee contracts and promote productivity, motivation and retention. 


\section{$\underline{\text { Final Citations }}$}

Allen, T., Golden, T., \& Shockley, K. (2015). "How Effective Is Telecommuting? Assessing the Status of Our Scientific Findings." Psychological Science in the Public Interest, 16(2), 40-68.

Alter, Jonathan. (1991). The generation game: A new book finds a rhythm in American history. Newsweek, 117(15), 66.

Ankli, R., \& Palliam, R. (2012). "Enabling a motivated workforce: Exploring the sources of motivation." Development and Learning in Organizations: An International Journal, 26(2), 7-10.

Au-Yong-Oliveira, M., Gonçalves, R., Martins, J., \& Branco, F. (2018). The social impact of technology on millennials and consequences for higher education and leadership. Telematics and Informatics, 35(4), 954-963.

Aziri, Brinkend. (2011). Job Satisfaction: A literature review. Management Research and Practice, 3(4), 77-86.

Bernardino, A., Roglio, K., \& Del Corso, J. (2012). Telecommuting and HRM: A case study of an information technology service provider. JISTEM - Journal of Information Systems and Technology Management, 9(2), 285-306.

Bennett, J., Prit, M., \& Price, S. (2012). Understanding the impact of generational issues in the workplace. Facilities. 30(7), 278-288.

Bishka, A. (2015). Soldering Motivation to Performance and Productivity. Performance Improvement, 54(5), 2-4.

Brown-Crowder, R., Britch, B., Jain, A., Korrapati, R., \& McGunagle, D. (2017). Work Motivation Theory: Identifying Multi-Generational Values in the Workplace, (dissertation) ProQuest Dissertations and Theses.

Calvasina, E., Calvasina, R., Calvasina, E. (2012) The Virtual Office: HRM Legal, Policy and Practice Issues. Allied Academies International Conference. 4(1), 1-7.

Cooke, G., et al. (2014). Dialing It in: A Missed Opportunity Regarding the Strategic Use of Telework?. Relations Industrielles, 69(3), 550-574. 
Dahlstrom, T. (2013). Telecommuting and Leadership Style. Public Personnel Management, 42(3), 438-451.

Davis, R., Cates, S. (2013). The Dark Side of Working in a Virtual World: An Investigation of the Relationship between Workplace Isolation and Engagement among Teleworkers. Journal of Human Resources and Sustainability Studies. 1(2), 9-13.

Daniels, Kevin D., et.al. (2000). Managing telework: Perspectives from human resource management and work psychology. $R \& D$ Enterprise: Asia Pacific, 3(4), 37-38.

DeArmond, S., Tye, M., Chen, P., Krauss, A., Apryl Rogers, D., \& Sintek, E. (2006). Age and Gender Stereotypes: New Challenges in a Changing Workplace and Workforce. Journal of Applied Social Psychology, 36(9), 2184-2214.

Di Martino, V., \& Wirth, L. (1990). Telework: A New Way of Working and Living. International Labour Review, 129(5), 529-54.

Downing, K., (2006). Next generation: What leaders need to know about the millennials, Leadership in Action. 26(3), 3-6.

Dubrin, A. (1991). Comparison of the Job Satisfaction and Productivity of Telecommuters versus in-House Employees: A Research Note on Work in Progress. Psychological Reports, 68(3_suppl), 1223-1234.

Eversole, B., Venneberg, D., Crowder, C., Ruona, W., \& Coates, T. (2012). "Creating a Flexible Organizational Culture to Attract and Retain Talented Workers Across Generations." Advances in Developing Human Resources, 14(4), 607-625.

Faisal Ahammad, M., Mook Lee, S., Malul, M., \& Shoham, A. (2015). Behavioral Ambidexterity: The Impact of Incentive Schemes on Productivity, Motivation, and Performance of Employees in Commercial Banks. Human Resource Management, 54(S1), S45-S62.

Forastero, A., Sjabadhyni, B, \& Mustika, D., M. (2018). What Millennials Want: How to Optimize Their Work. Psikohumaniora: Jurnal Penelitian Psikologi, 3(1), 1-16.

Forgács, T. (2010). Empirical research findings on telework: Management experiences and attitudes. Business and Economic Horizons, 1(1), 6. 
Gajendran, R. S., \& Harrison, D. A. (2007). The good, the bad, and the unknown about telecommuting: Meta-analysis of psychological mediators and individual consequences. Journal of Applied Psychology, 92(6), 1524-1541.

GAO. (2013). 2013 Annual Report (pp. 1-283). Washington DC. Retrieved from https://www.gao.gov/products/GAO-13-279SP

Gassan Issa AL-Omari, Rami Hanandeh, Mustafa Mahmoud Al-Somaidaee, Mufleh Amin Al Jarrah, \& Sakher Alnajdawi. (2020). Work-life balance and its impact on employee satisfaction on five star hotels. Management Science Letters, 10(4), 871-880.

Global Workplace Analytics. (2020, April 12). Work-at-Home After Covid-19 Our Forecast. Retrieved from https://globalworkplaceanalytics.com/work-at-home-after-covid-19-ourforecast

Gifford, J. (2015) Getting Under the Skin of Workplace Conflict: Tracing the experiences of emplooyees. Chartered Institute of Personnel and Development. 1-31.

Golden, T., Veiga, J., \& Dino, R. (2008). The impact of professional isolation on teleworker job performance and turnover intentions: Does time spent teleworking, interacting face-toface, or having access to communication-enhancing technology matter? The Journal of Applied Psychology, 93(6), 1412-1421.

Hart, R., Natt Och Dag, K., Manderscheid, S., \& Ardichvili, A. (2016). Informal Virtual Mentoring for Team Leaders and Members: Emergence, Content, and Impact. Advances in Developing Human Resources, 18(3), 352-368.

Hartman, R. I., Stoner, C. R., \& Arora, R. (1991). An investigation of selected variables affecting telecommuting productivity and satisfaction. Journal of Business and Psychology, 6(2), $207-225$.

Herzberg, F. (1971). Work and the nature of man. New York: World Publishing.

Heater, B. (2020, May 12). Twitter says staff can continue working from home permanently. Retrieved from https://techcrunch.com/2020/05/12/twitter-says-staff-can-continueworking-from-home-permanently/

Hong, J., Yang, S., Wang, L., Chiou, E., Su, F., \& Huang, S. (1995). Impact of employee benefits on work motivation and productivity. International Journal of Career Management, 7(6), 10-14. 
Hoornweg, N., Peters, P., \& Van Der Heijden, B. (2016). Finding the Finding the Optimal Mix between Telework and Office Hours to Enhance Employee Productivity: A Study into the Relationship between Telework Intensity and Individual Productivity, with Mediation of Intrinsic Motivation and Moderation of Office Hours. Emerald Group Publishing Limited, 16, 1-28.

Hering, B. B. (2015, May 18). The History of Telecommuting and Where It Stands Now. Retrieved from https://www.flexjobs.com/blog/post/the-history-of-telecommuting-standsnow/.

Kuo, P., Woo, H., \& Bang, N. (2017). Advisory Relationship as a Moderator Between Research Self-Efficacy, Motivation, and Productivity Among Counselor Education Doctoral Students. Counselor Education and Supervision, 56(2), 130-144.

Kaczmarczyk, S. (2008). Telework: Breaking new ground. The Public Manager 37(1), 63-67.

Lachapelle, U., Tanguay, G., \& Neumark-Gaudet, L. (2018). Telecommuting and sustainable travel: Reduction of overall travel time, increases in non-motorised travel and congestion relief? Urban Studies, 55(10), 2226-2244.

Lam, A., \& Lambermont-Ford, J. (2010). Knowledge sharing in organisational contexts: A motivation-based perspective. Journal of Knowledge Management, 14(1), 51-66.

Leuty, M., \& Hansen, J. (2014). Teasing apart the relations between age, birth cohort, and vocational interests. Journal of Counseling Psychology, 61(2), 289-298.

Lundberg, C., Gudmundson, A., \& Andersson, T. (2009). Herzberg's Two-Factor Theory of work motivation tested empirically on seasonal workers in hospitality and tourism. Tourism Management, 30(6), 890-899.

Maria-Cristina Iorgulescu. (2016). GENERATION Z AND ITS PERCEPTION OF WORK. Cross-Cultural Management Journal, 18(1), 47-54.

Maruyama, T., \& Tietze, S. (2012). From anxiety to assurance: Concerns and outcomes of telework. Personnel Review, 41(4), 450-469.

Mirjana Radovic-Markovic. (2014). Virtual Organizations: Employee Competency and Managerial Issues. Annals of the University of Petrosani: Economics, 14(1)287-290. 
Nafukho, M. F., Hairston, N., \& Brooks, K. (2004) Human Capital Theory: Implications for Human Resource Development, Human Resource Development International, 7(4), 545554.

Parker, K., Morin, R., \& Horowitz, J. M. (2019, December 31). The future of work in the automated workplace. Retrieved from https://www.pewsocialtrends.org/2019/03/21/thefuture-of-work-in-the-automated-workplace/

Pasini, R., \& Back, K. (2018, October 1). A History of Telecommuting: Remote Work's Evolution Explained. Retrieved from

https://www.virtualvocations.com/blog/telecommuting-job-search-help/history-of-teleco mmuting-remote-work/.

PWC. (2013). PwC's Next Gen: A global generational study (pp. 1-16). Retrieved from https://www.pwc.com/gx/en/hr-management-services/pdf/pwc-nextgen-study-2013.pdf

Pyoria, P. (2011). Managing Telework: Risk Fears and Rules. Management Research Review. 34(4). 386-399

Sale, J., \& Jones, Steve. (2019). Mapping motivation for engagement (Complete guide to mapping motivation). New York: Routledge.

Schweitzer, \& Duxbury. (2006). Benchmarking the Use of Telework Arrangements in Canada. Canadian Journal of Administrative Sciences / Revue Canadienne Des Sciences De L'Administration, 23(2), 105-117.

Schawbel, D. (2018, November). Survey: Remote workers are more disengaged and more likely to quit. Harvard Business Review Digital Articles, 1-4.

SHRM. (2010). 2010 Employee Benefits: Examining Employee Benefits in the Midst of a Recovering Economy (pp. 1-88). Alexandria, VA. Retrieved from https://www.shrm.org/hr-today/news/hr-news/documents/10-0280 employee benefits survey report-fnl.pdf

Tarallo, Mark. How to Create an Effective Teleworking Program. 16 Aug. 2019, www.shrm.org/resourcesandtools/hr-topics/employee-relations/pages/how-to-create-aneffective-teleworking-program.aspx.

Telework Legislation. (2014). Retrieved from https://www.telework.gov/guidance-legislation/telework-legislation/background-history/. 
Tsaur, S., \& Yen, C. (2018). Work-leisure conflict and its consequences: Do generational differences matter? Tourism Management, 69, 121-131.

Torten, R., Reaiche, C., \& Caraballo, E.L. (2016). Teleworking in the new millennium. The Journal of Developing Areas 50(5), 317-326.

Vitry, M. J. (2014). Confluence Of Factors On Leaders'Decisions To Implement A Telework Program: A Qualitative Multiple Case Study (dissertation). ProQuest, Ann Arbor, MI.

Weeks, K., \& Schaffert, P. (2019). Generational Differences in Definitions of Meaningful Work: A Mixed Methods Study. Journal of Business Ethics, 156(4), 1045-1061.

Wise, T. (2016). Trust in virtual teams: Organization, strategies and assurance for successful projects. London [England]; New York, New York: Routledge.

Yang, S., \& Guy, M. (2006). GENXERS VERSUS BOOMERS: Work Motivators and Management Implications. Public Performance \& Management Review, 29(3), 267-284. 